\title{
Preparation and investigations of thermal properties of copper oxide, aluminium oxide and graphite based on new organic phase change material for thermal energy storage
}

\author{
MURAT GENC ${ }^{1}$, BETUL INCI ${ }^{1}$, ZUHAL KARAGOZ GENC ${ }^{2, *}$, CANAN AKSU CANBAY ${ }^{3}$

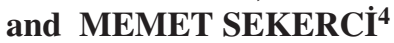 \\ ${ }^{1}$ Faculty of Science and Arts, Department of Chemistry, Adiyaman University, 02040 Adiyaman, Turkey \\ ${ }^{2}$ Faculty of Engineering, Department of Metallurgy and Materials Engineering, Adiyaman University, \\ 02040 Adiyaman, Turkey \\ ${ }^{3}$ Faculty of Science, Department of Chemistry, Firat University, 23119 Elazig, Turkey \\ ${ }^{4}$ Faculty of Science, Department of Physics, Firat University, 23119 Elazig, Turkey
}

MS received 24 February 2014; revised 8 May 2014

\begin{abstract}
The effects of copper oxide, aluminium oxide and graphite on the thermal and structural properties of the organic phase change material (PCM) were investigated. Ethyl 2-(1H-benzotriazole-1-yl)acetate was selected as the pure PCM. Fourier transform infrared (FT-IR) spectroscopy, X-ray, energy dispersive X-ray (EDX) and scanning electron microscope (SEM) were used to determine the chemical structure, crystalloid phase, chemical composition and microstructure of the composites, respectively. The thermal properties were investigated by differential scanning calorimetry and thermogravimetric analyzer. The FT-IR analyses indicated that there was no chemical interaction between the pure PCM and the supporting materials such as copper oxide, aluminium oxide and graphite. The X-ray diffractograms of the samples were nearly the same, but the peak intensities changed according to the supporting materials. The SEM results showed that the $\mathrm{C}, \mathrm{N}$ and $\mathrm{O}$ elements were well adsorbed into the porous network of the graphite, $\mathrm{Al}_{2} \mathrm{O}_{3}$ and $\mathrm{CuO}$. According to the supporting materials, the graphite had the minimum porosity and the maximum crystallite size.
\end{abstract}

Keywords. Composite materials; DSC; thermal energy storage.

\section{Introduction}

Phase change materials (PCMs), also called latent heatstorage materials, are a series of useful materials capable of storing and releasing large heat energy with slight or no temperature change. In recent years, many types of the PCMs have received attention for various applications in waste heat recovery, smart housing, temperature-control, green houses, solar energy, and heat regulation of electronics, biomedical and biological carrying systems. ${ }^{1-7}$

Many organic and inorganic PCMs such as fatty acids, esters and salt hydrates have been studied for latent heatstorage applications. ${ }^{8-11}$ Among the PCMs investigated, the organic PCMs have been widely used due to the higher latent heat-storage capacity and suitable thermal properties such as little or no supercooling, low vapour pressure, good thermal and chemical stability. But, they have low thermal conductivity and need encapsulating in order to prevent the leakage of the melted PCM during the phase change process. ${ }^{12,13}$ However, these problems can be solved by using form-stable PCM composites.

In this experiment the synthesis, thermal and structural properties of the synthesis, of ethyl 2-(1H-benzotriazole-1-yl)

\footnotetext{
*Author for correspondence (zuhalkaragoz23@gmail.com)
}

acetate and ethyl 2-(1H-benzotriazole-1-yl)acetate, supported with graphite, $\mathrm{Al}_{2} \mathrm{O}_{3}$ and $\mathrm{CuO}$, were investigated.

Up to now, the synthesis and properties of ethyl 2- $(1 H-$ benztriazole-1-yl) acetate, supported with the different materials, is not reported. Besides, the organic PCMs (fatty acids, esters, etc.) have low thermal stability, and they are not widely used in the thermal-storage systems. In this research, the graphite, $\mathrm{Al}_{2} \mathrm{O}_{3}$ and $\mathrm{CuO}$ improved the thermal stability, and the high latent heat-storage capacity of the nano particles supported PCMs due to the synergistic effect between the nanoparticles and ethyl 2-(1H-benzotriazole-1yl)acetate, especially the graphite-supported PCM. Therefore, the graphite-supported composite can be applied in building energy conversion and heat recovery systems for thermal energy storage.

\section{Experimental}

The morphology and microstructure of the pure PCM and composite-based PCMs were observed using a scanning electron microscope (SEM, LEO 440 model). The structural analysis of organic PCM and composite-based PCMs were analysed by Fourier transform infrared (FT-IR) spectrometer. The spectra were recorded on a Perkin-Elmer infrared spectrometer as $\mathrm{KBr}$ pellets with a resolution of 
$4 \mathrm{~cm}^{-1}$ in the range of $400-4000 \mathrm{~cm}^{-1}$. The thermal properties of PCMs were obtained using a differential scanning calorimeter (DSC, Shimadzu $60 \mathrm{WS}$ ). DSC curve was tested with a heating rate of $5^{\circ} \mathrm{C} \mathrm{min}^{-1}$ in nitrogen atmosphere. The thermal stability of the composite PCMs was studied by means of thermogravimetry on a Shimadzu TA-60WS, from room temperature to $600^{\circ} \mathrm{C}$ with a heating rate of $15^{\circ} \mathrm{C} \mathrm{min}-1$ and air atmosphere. The chemical compositions of the alloys were determined by energy dispersive X-ray (EDX) analysis. The X-ray diffraction measurements were carried out in a RigakuRadB-DMAX II diffractometer using $\mathrm{CuK}_{\alpha}(\lambda=1.5405 \AA)$ radiation operating at $40 \mathrm{kV}$ and $30 \mathrm{~mA}$. The Bragg's angle $2 \theta$ is set in the range between 0 and $60^{\circ}$ with a scanning rate of $6^{\circ} \mathrm{min}^{-1}$. The crystallinities

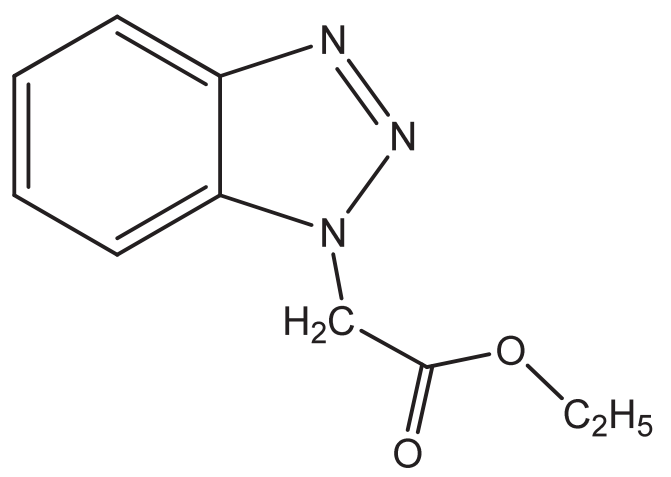

Figure 1. Structure of the organic PCM. of the samples were calculated by using the peak resolution observed in the XRD measurements. The thermal reliability of the organic PCM and the composite-based PCMs was evaluated with respect to change in phase temperatures and latent heats, after a large number of thermal cyclings. The thermal cycling consisted of exposing form-stable composite PCMs to a melting and freezing process. This was done by Applied Biosystem 96-well Thermal Cycler.

\subsection{Preparation of PCMs}

2.1a Synthesis of ethyl 2-(1H-benzotriazole-1-yl)acetate: $1 H$-benzotriazole $(0.1 \mathrm{~mol})$ and sodium hydroxide $(0.1 \mathrm{~mol})$ were dissolved in ethanol $(150 \mathrm{ml})$, and an ethanol $(25 \mathrm{ml})$ solution of ethyl 2-bromoacetate $(0.1 \mathrm{~mol})$ was added dropwise. After stirring for $4 \mathrm{~h}$ at room temperature, the mixture set part to crystallize at room temperature for several days for giving colourless block crystals and it was filtered, ${ }^{14,15}$ the colourless, ${ }^{1} \mathrm{H}-\mathrm{NMR}$ (400 MHz, $\mathrm{CHCl}_{3}$-d): 1.29-1.26 (t, $3 \mathrm{H}$, J: $\left.8 \mathrm{~Hz}, \mathrm{CH}_{3}\right), 4.29-4.24$ (q, 2H, J: $\left.4 \mathrm{~Hz} \mathrm{O}-\mathrm{CH}_{2}\right), 5.44$ (s, $2 \mathrm{H}$, N-CH ${ }_{2}$ ), 7.59-7.34 (m, 3H Ar-H) 8.1 (d, 1H, J: 8 Hz Ar-H; ${ }^{13} \mathrm{C}-\mathrm{NMR}\left(75 \mathrm{MHz}, \mathrm{CHCl}_{3}\right.$-d):166, 145, 133, 123, 120, 118, $112,62,49,14$.

$2.1 \mathrm{~b}$ Preparation of nanoparticle supported PCMs: Onestep method was selected to prepare the PCMs. To observe the stability of the composite, the PCMs consisting of ethyl 2-( $1 \mathrm{H}$-benzotriazole-1-yl)acetate, graphite, $\mathrm{Al}_{2} \mathrm{O}_{3}$ and $\mathrm{CuO}$

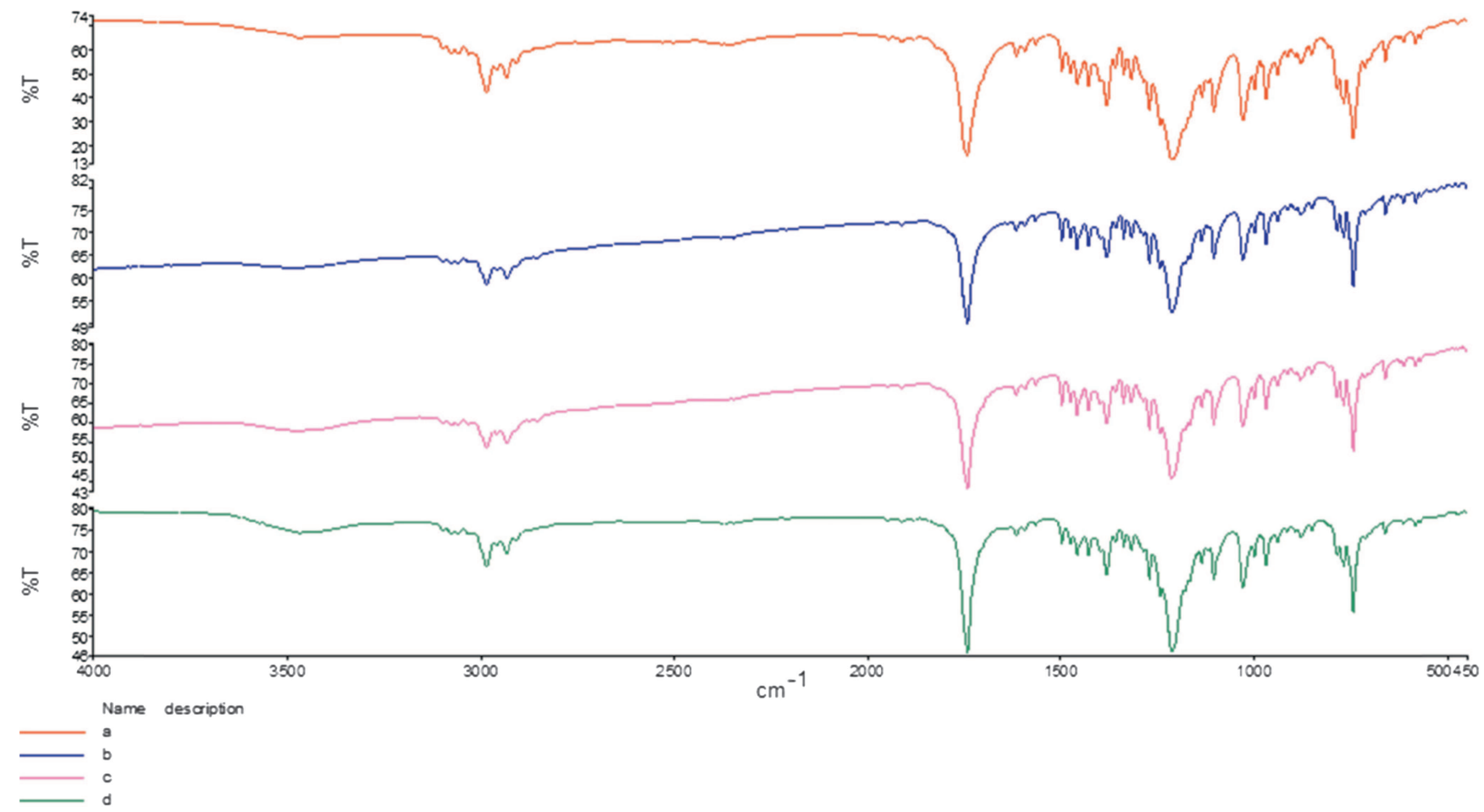

Figure 2. FT-IR spectrum of the PCMs. 
nanoparticles, and different dispersants were prepared. All of the preparation processes were performed by using an ultrasonic vibrator for $8 \mathrm{~h}$. A longer time of the high-energy sonication would introduce defects. The ultrasonic temperature was above $68.59^{\circ} \mathrm{C}$ to ensure that the samples were kept sufficiently above the melting point of the pure PCM (figure 1).

\section{Results and discussion}

In the IR spectrum of the samples (figure $2 \mathrm{a}$ ), the characteristic peak of the benzotriazole at $1742 \mathrm{~cm}^{-1}$ corresponds to $v(\mathrm{C}=\mathrm{O})$. The stretching vibration of the $\mathrm{C}-\mathrm{O}$ group appears at $1210 \mathrm{~cm}^{-1}$. The peaks 3099-3059 and 2986-2906 $\mathrm{cm}^{-1}$ are due to the aromatic $\mathrm{CH}$ and aliphatic $\mathrm{CH}$, respectively. The stretching vibration of the $\mathrm{C}=\mathrm{N}$ is at $1616 \mathrm{~cm}^{-1}$. The peak at $1594 \mathrm{~cm}^{-1}$ corresponds to the stretching vibration of the aromatic group of $\mathrm{C}=\mathrm{C}$. As seen in figure 2, the absorption peaks of pure PCM at 3099-3059, 2986-2906, 1742, 1616, $1594,1210 \mathrm{~cm}^{-1}$ also appear in the other PCM spectra.

This result shows that the pure PCM was dispersed in the porous network of the nanoparticles. It is also found that there is no shift in the absorption peaks of the pure PCM, when compared with the spectra of the nanoparticle-additive PCMs. This result indicates that there is no chemical interaction between the functional groups of the benztriazole and nanoparticles. The pure PCM was retained easily in the pores of the nanoparticles and so, the leakage of the melted pure PCM from the composites was prevented.

The EDX analysis was performed to observe the elements and impurities in the samples. In figure 3, only $\mathrm{C}, \mathrm{N}$ and $\mathrm{O}$ elements were determined for ethyl 2- $(1 \mathrm{H}-$ benzotriazole-1-yl)acetate and graphite-PCM samples. However, these $\left(\mathrm{Al}_{2} \mathrm{O}_{3}-\mathrm{PCM}\right.$ and $\left.\mathrm{CuO}-\mathrm{PCM}\right)$ have distinct peaks of $\mathrm{Al}$ and $\mathrm{Cu}$, respectively, as shown in EDX analysis. This indicates that $\mathrm{Al}_{2} \mathrm{O}_{3}-\mathrm{PCM}$ contains $\mathrm{C}, \mathrm{N}, \mathrm{O} \mathrm{Al}$ elements, and CuO-PCM contains $\mathrm{C}, \mathrm{N}, \mathrm{O}$ and $\mathrm{Cu}$ elements.

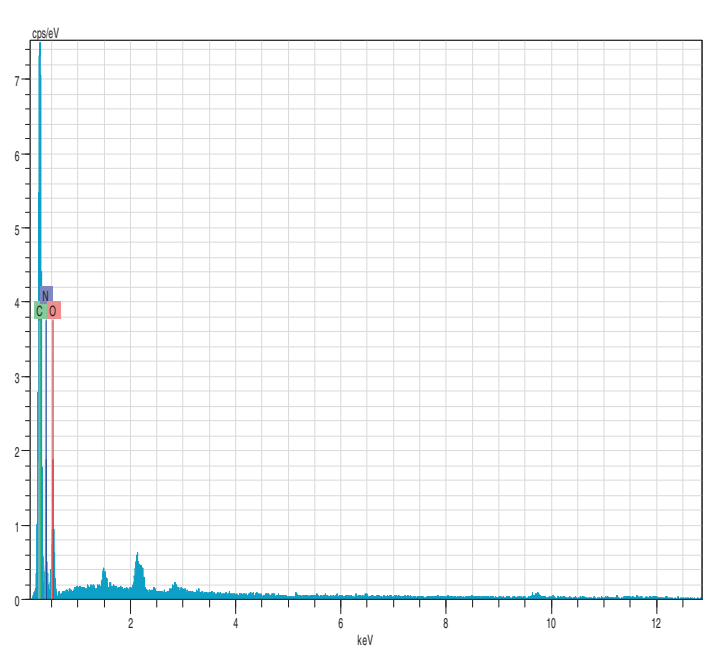

(a)

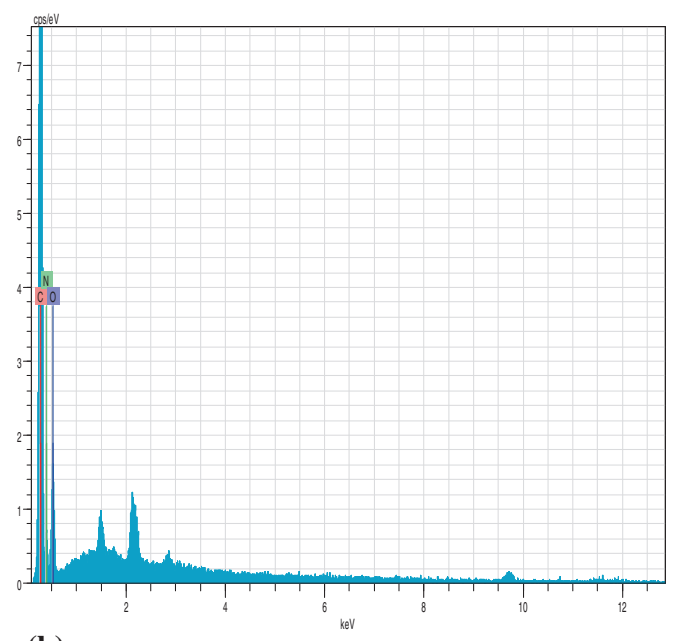

(b)
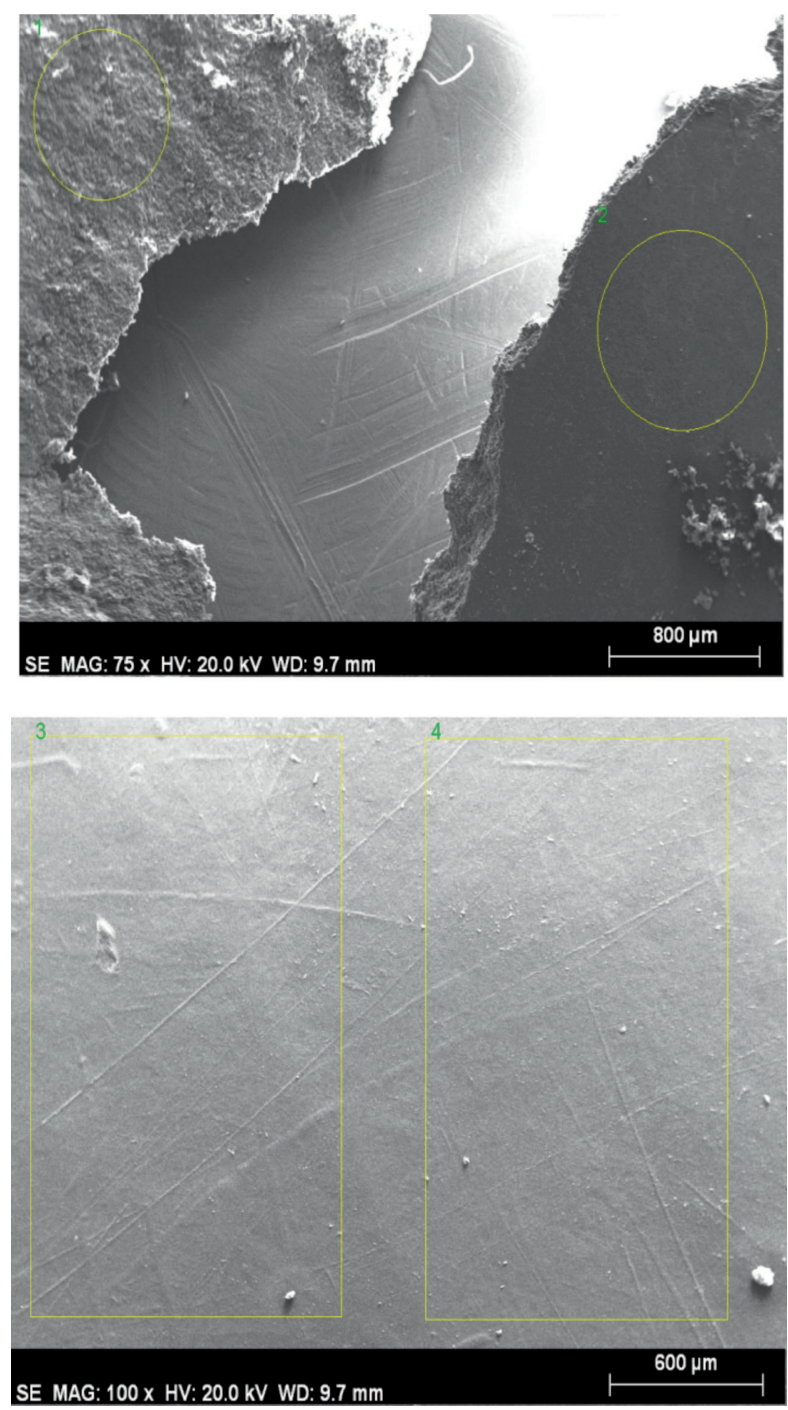

Figure 3. EDX photographs of samples: (a) pure PCM, (b) graphite-PCM, (c) $\mathrm{Al}_{2} \mathrm{O}_{3}-\mathrm{PCM}$ and (d) $\mathrm{CuO}-\mathrm{PCM}$. 


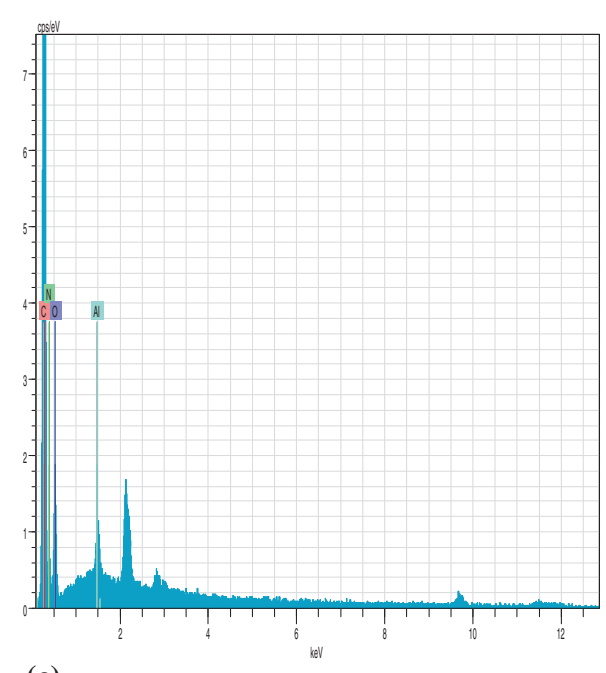

(c)

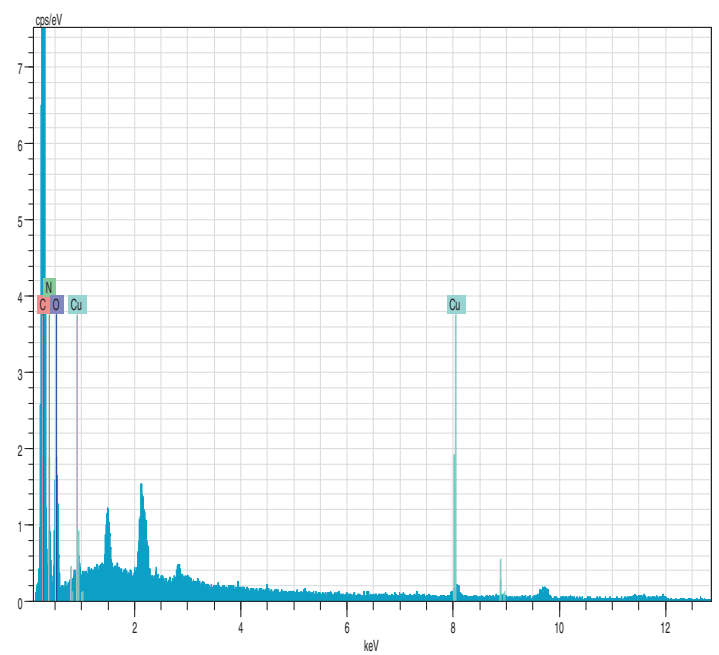

(d)
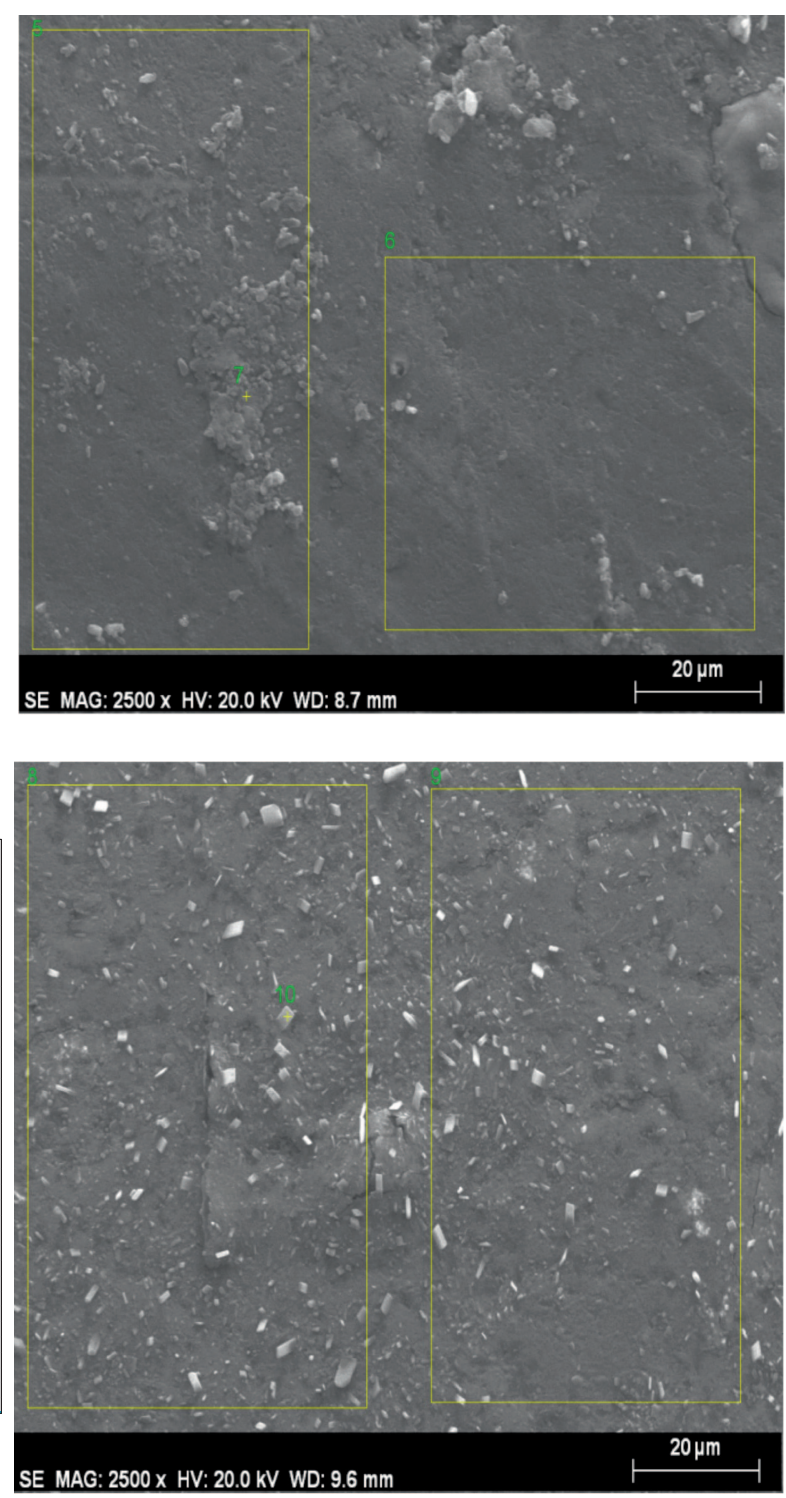

Figure 3. Continued.

The SEM images of PCMs with different magnifications are depicted in figure 4 . The figure shows the surface morphology of the samples. According to these SEM images, it can be concluded that: sample (A) has porous structure, and the graphite-PCM, $\mathrm{Al}_{2} \mathrm{O}_{3}-\mathrm{PCM}$ and $\mathrm{CuO}-\mathrm{PCM}$ samples have smooth structure. This can be explained by the structure of the graphite, $\mathrm{Al}_{2} \mathrm{O}_{3}$ and $\mathrm{CuO}$. As known, graphite, $\mathrm{Al}_{2} \mathrm{O}_{3}$ and $\mathrm{CuO}$ have multiple pores with many inner surfaces, which can be easily permeated with the matrix. So, the surfaces of the graphite-PCM, $\mathrm{Al}_{2} \mathrm{O}_{3}-\mathrm{PCM}$ and $\mathrm{CuO}-\mathrm{PCM}$ samples have smooth structures because the supporting materials diffuse well in matrix.

To reveal the crystalline morphology of the ethyl 2( $1 \mathrm{H}$-benzotriazole-1-yl)acetate, graphite-PCM, $\mathrm{Al}_{2} \mathrm{O}_{3}-\mathrm{PCM}$ and $\mathrm{CuO}-\mathrm{PCM}$, the $\mathrm{X}$-ray diffraction measurements were made at room temperature. The XRD patterns are shown in figure 5 , and it is clear that the relative intensity and the
$2 \theta$ of the diffraction peaks of these four spectra are identical. As shown in figure 3, all samples (a-d) have similar diffraction patterns, and so are their diffraction angles and crystal plane distances. In the diffraction patterns of all samples, two strong diffraction peaks appear at $9.4^{\circ}$ and $27.9^{\circ}$. The other peaks observed at $17.6^{\circ}, 21.5^{\circ}, 23^{\circ}$ and $35^{\circ}$ in all samples are clear, but the intensities of these peaks varied. This result indicates that all samples acquire similar crystal structure. This crystal structure behaviour of the samples is mainly due to the matrix. And all these samples have the same matrix, which were doped with graphite, $\mathrm{Al}_{2} \mathrm{O}_{3}$ and $\mathrm{CuO}$. So, when we consider the X-ray measurements, this behaviour is expected. The crystallinity in samples changed according to the doping material and this was observed from the peak heights of the diffraction patterns. This is generally attributed to the characteristic activity of the union of matrix and doping material. The differences between these peaks 

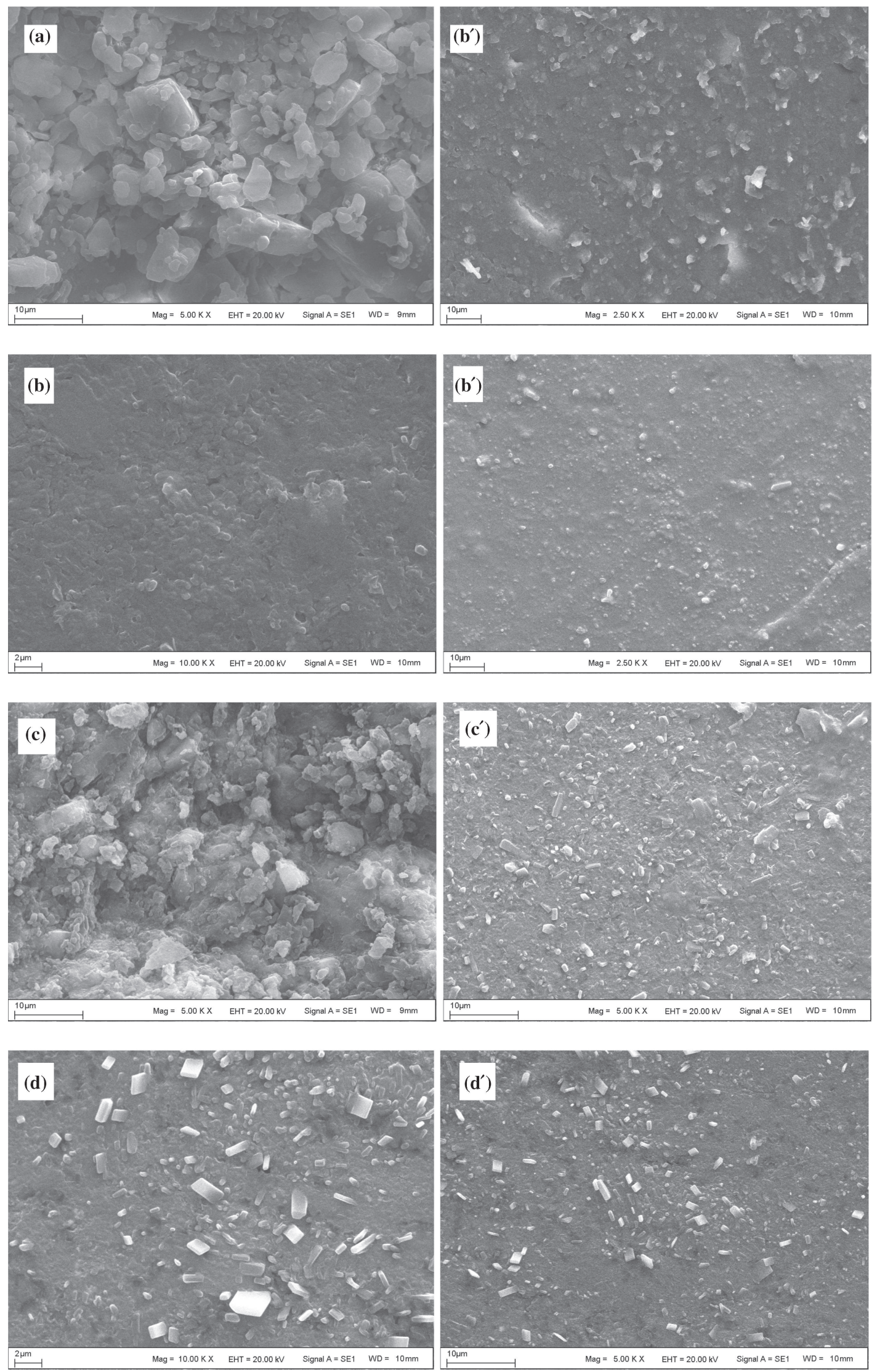

Figure 4. SEM photographs of samples: (a) pure PCM, (b) graphite-PCM, (c) $\mathrm{Al}_{2} \mathrm{O}_{3}-\mathrm{PCM}$ and (d) CuO-PCM. 


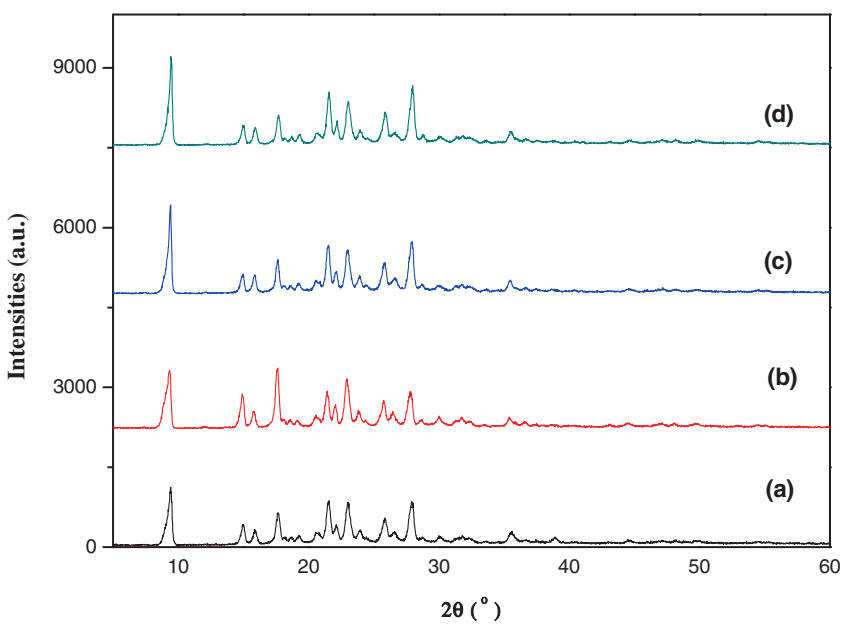

Figure 5. XRD patterns of samples: (a) pure PCM, (b) graphite$\mathrm{PCM},(\mathbf{c}) \mathrm{Al}_{2} \mathrm{O}_{3}-\mathrm{PCM}$ and (d) $\mathrm{CuO}-\mathrm{PCM}$.

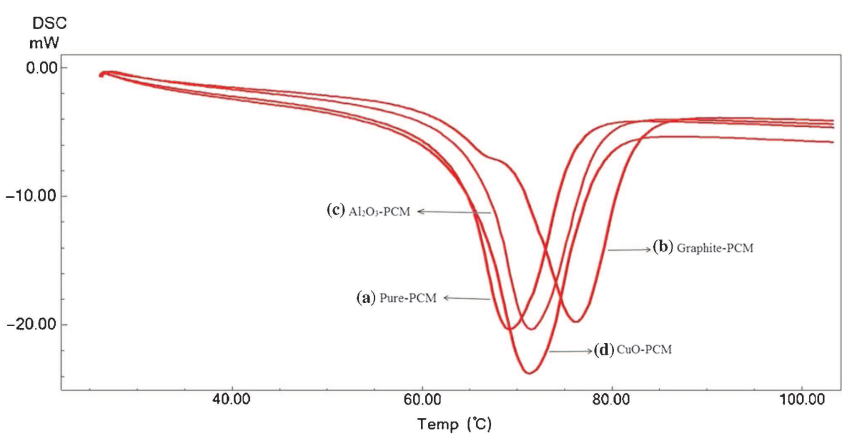

Figure 6. DSC curves of samples: (a) pure PCM, (b) graphite$\mathrm{PCM}$, (c) $\mathrm{Al}_{2} \mathrm{O}_{3}-\mathrm{PCM}$ and (d) CuO-PCM.

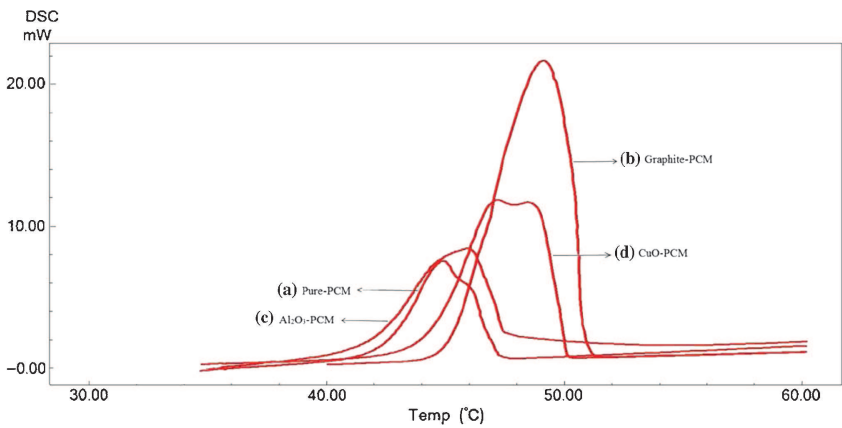

Figure 7. DSC curves of samples: (a) pure PCM, (b) graphite$\mathrm{PCM},(\mathbf{c}) \mathrm{Al}_{2} \mathrm{O}_{3}-\mathrm{PCM}$ and (d) $\mathrm{CuO}-\mathrm{PCM}$. are diffraction peak height, and this means that the crystallites and the degree of crystallinity in samples change. So, the crystallite sizes of the samples were calculated. The average crystallite size $D$ for the samples were determined by Debye-Scherrer equation,

$$
D=\frac{0.9 \lambda}{B_{1 / 2} \cos \theta}
$$

where $\lambda$ is the wavelength of the $\mathrm{X}$-ray ( $\mathrm{CuK}_{\alpha}$ radiation), $\beta$ is the peak full-width at half-maximum (FWHM), and $\theta$ is the Bragg angle. The calculated crystallite size values for the samples are 19.3, 25.62, 25.3 and $21.27 \mathrm{~nm}$, respectively.

The DSC curves of the PCMs are shown in figures 6 and 7, while the data of extrapolated melting peak temperatures $\left(T_{\mathrm{m}}\right)$, enthalpy of melting $\left(\Delta H_{\mathrm{m}}\right)$, crystallization peak temperature $\left(T_{\mathrm{c}}\right)$ and the enthalpy of crystallization $\left(\Delta H_{\mathrm{c}}\right)$ are listed in table 1 . The results show that the phase transition temperatures of composite PCMs are higher than that of the pure PCM. According to these results, we can easily say that, the phase transition temperatures and enthalpies of melting and crystallization for pure PCM could be adjusted, and this would be highly desirable for different applications.

The thermal stabilities of pure PCM with graphite, $\mathrm{Al}_{2} \mathrm{O}_{3} \mathrm{CuO}$ and without nanoparticles were evaluated by thermogravimetric analysis. The TGA curves of the composites are shown in figure 8 . The maximum decomposition

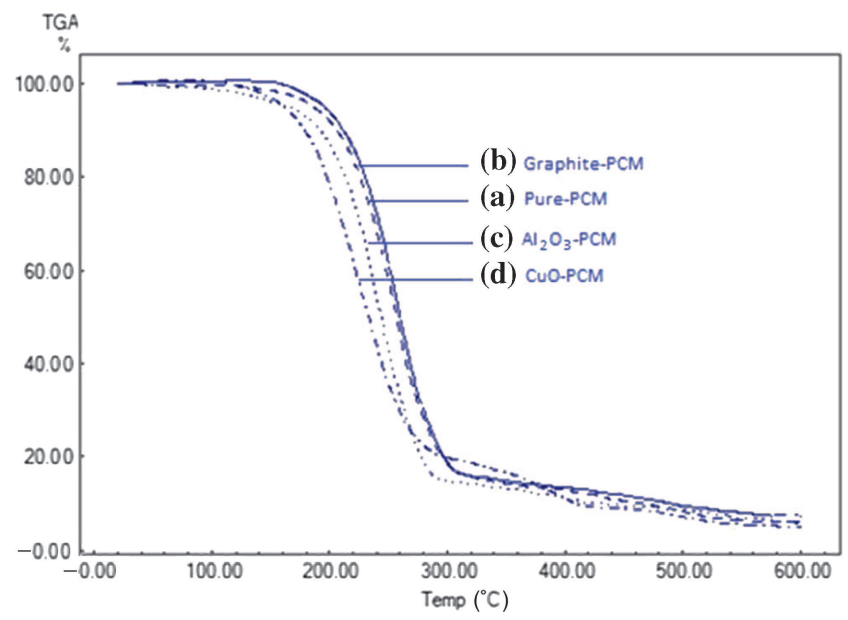

Figure 8. TG curves of samples: (a) pure PCM, (b) graphite$\mathrm{PCM},(\mathbf{c}) \mathrm{Al}_{2} \mathrm{O}_{3}-\mathrm{PCM}$ and (d) $\mathrm{CuO}-\mathrm{PCM}$.

Table 1. DSC data of organic PCM, graphite-PCM, $\mathrm{Al}_{2} \mathrm{O}_{3}-\mathrm{PCM}$ and $\mathrm{CuO}-\mathrm{PCM}$.

\begin{tabular}{|c|c|c|c|c|}
\hline \multirow[b]{2}{*}{ Sample name } & \multicolumn{2}{|c|}{ Melting } & \multicolumn{2}{|c|}{ Cooling } \\
\hline & $\begin{array}{c}\text { Melting temperature, } \\
T_{\mathrm{m}}\left({ }^{\circ} \mathrm{C}\right)\end{array}$ & $\begin{array}{c}\text { Melting latent } \\
\text { heat } \Delta H_{\mathrm{m}}\left(\mathrm{kj} \mathrm{kg}^{-1}\right)\end{array}$ & $\begin{array}{c}\text { Cooling temperature, } \\
T_{\mathrm{c}}\left({ }^{\circ} \mathrm{C}\right)\end{array}$ & $\begin{array}{c}\text { Cooling latent } \\
\text { heat, } \Delta H_{\mathrm{c}}\left(\mathrm{kj} \mathrm{kg}^{-1}\right)\end{array}$ \\
\hline Organic-PCM & 68.59 & 65.10 & 45.91 & 78.66 \\
\hline Graphite-PCM & 77.32 & 97.45 & 49.15 & 106.90 \\
\hline $\mathrm{A}_{2} \mathrm{O}_{3}-\mathrm{PCM}$ & 71.80 & 67.93 & 44.93 & 76.06 \\
\hline CuO-PCM & 72.33 & 74.39 & 47.15 & 88.36 \\
\hline
\end{tabular}


Table 2. TGA data of organic PCM, graphite-PCM, $\mathrm{Al}_{2} \mathrm{O}_{3}-\mathrm{PCM}$ and $\mathrm{CuO}-\mathrm{PCM}$.

\begin{tabular}{lll}
\hline $\begin{array}{l}\text { Sample } \\
\text { name }\end{array}$ & $\begin{array}{l}\text { Temperature } \\
\left({ }^{\circ} \mathrm{C}\right)\end{array}$ & $\begin{array}{l}\text { Charred residue } \\
\text { amount }(\%)\left(600^{\circ} \mathrm{C}\right)\end{array}$ \\
\hline Pure-PCM & 220 & 8.5 \\
Graphite-PCM & 218 & 8.61 \\
$\mathrm{Al}_{2} \mathrm{O}_{3}-\mathrm{PCM}$ & 206 & 7.61 \\
$\mathrm{CuO}-\mathrm{PCM}$ & 184 & 6.1 \\
\hline
\end{tabular}

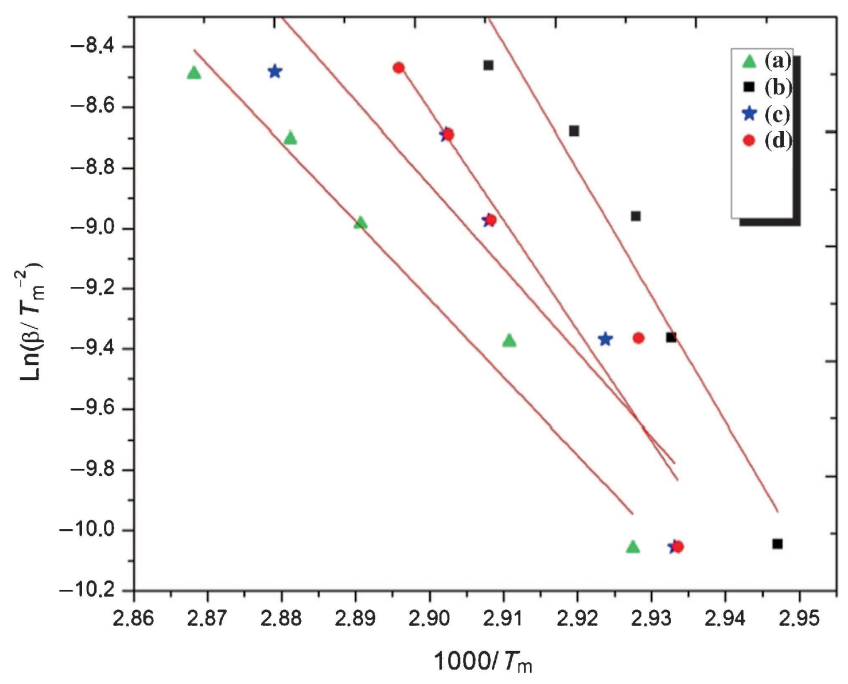

Figure 9. The Kissinger plot of curves of samples: (a) pure PCM, (b) graphite-PCM, (c) $\mathrm{Al}_{2} \mathrm{O}_{3}-\mathrm{PCM}$ and (d) $\mathrm{CuO}-\mathrm{PCM}$.

temperature $T_{\max }$ and the charred residue at $600^{\circ} \mathrm{C}$ are listed in table 2.

The weight loss features of the composite-based PCMs were similar to the graphite-PCM, $\mathrm{Al}_{2} \mathrm{O}_{3}-\mathrm{PCM}$ and $\mathrm{CuO}$ PCM during the initial stage. However, the thermal stability temperature for the graphite-PCM was $3-4^{\circ} \mathrm{C}$, higher than that of the other nanoparticle-additive PCMs. This result indicates that the graphite-PCM has the advantage of forming a protective layer on the surface of the ethyl $2-(1 \mathrm{H}-$ benzotriazole-1-yl)acetate, which may restrict the thermal degradation of the pure PCM in the composites.

Activation energy is one of the kinetic parameters obtained from thermal measurements (DSC). The activation energy changes significantly with temperature and, due to this, various rates of heating and cooling are used to calculate the activation energy. If the heating rate is changed, the peak temperature on the DSC curve is also changed. The variation in the peak temperature with heating rate is governed only by the activation energy $(E) .{ }^{16}$ The activation energy could be determined in terms of the Kissinger equation:

$$
\operatorname{In}\left(\frac{\beta}{T_{\mathrm{p}}^{2}}\right)=-\frac{E_{\mathrm{a}}}{R}\left(\frac{1}{T_{\mathrm{p}}}\right)+C
$$

where $\beta$ is the heating rate (chosen as 5, 10, 15, 20 and $25^{\circ} \mathrm{C} \mathrm{min}{ }^{-1}$ in this experiment), $T_{\mathrm{p}}$ is the temperature of the maximum melting endothermic peak and $E_{\mathrm{a}}$ the apparent activation energy of the PCMs. Plotting In $\left(\beta / T_{\mathrm{p}}^{2}\right)$ vs. $1 / T_{\mathrm{p}}$ should give a straight line. The slope of the line $-E_{\mathrm{a}} / R$ is used to determine the apparent activation energy. Figure 9 shows the Kissinger plot for the ethyl 2-(1H-benztriazole-1yl)acetate with nanoparticles. The apparent activation energy for the pure organic PCM was determined to be $236,69 \mathrm{kj}$ $\mathrm{mol}^{-1}$ by the Kissinger plot shown in figure 9. Similarly, the phase change activation energies for graphite-PCM, $\mathrm{Al}_{2} \mathrm{O}_{3}$ PCM and CuO-PCM were determined to be 346.86, 215 and $308.06 \mathrm{kj} \mathrm{mol}^{-1}$, respectively. This shows that the phase change energy of graphite-PCM was higher than those of the other PCMs and pure PCM. Each sample has different activation energy value, and this is related with the structure of investigated sample. The supporting material into matrix changes as graphite, $\mathrm{Al}_{2} \mathrm{O}_{3}$ and $\mathrm{CuO}$, so these supporting materials also change the structure of the sample and this affected the activation energy values.

\section{Conclusion}

The preparation and characterization of the nanoparticleadditive PCMs and pure PCM are reported. The pure PCM was used as PCM for the thermal energy storage, and the nanoparticles (graphite, $\mathrm{Al}_{2} \mathrm{O}_{3}$ and $\mathrm{CuO}$ ) are used as supporting materials. The phase change temperature and the latent heat of graphite-PCM composite PCM have greater heat storage rate than that of organic PCM and the other nano-supported PCMs. When we compare the microstructural (XRD, SEM) and thermal (DSC) analyses, the results are consistent with each other. The crystallite size calculated according to Debye-Scherrer equation using FWHM indicated that the sample graphite-PCM had the maximum crystallite size, and, as seen in SEM images, the minimum porosity was observed in the sample graphite-PCM. In addition to these results, the maximum enthalpy $(\Delta H)$ value observed from DSC analysis belongs to the sample graphite-PCM, and the sample pure PCM has the minimum crystallite size and the minimum enthalpy value. So, it can be concluded that the enthalpy value varies according to the crystallite size and the configuration of the atoms in the molecule.

\section{Acknowledgement}

We gratefully acknowledge the financial support provided by Adiyaman University Research Foundation (FEFYL/20120005).

\section{References}

1. Feng L, Zheng J, Yang H, Guo Y, Li W and Li X 2011 Sol. Energ. Mater. Sol. C 95644

2. Inaba H 2000 Int. J. Thermal Sci. 39991

3. Kurklu A 1998 Renew. Energ. 1389

4. Li W D and Ding E Y 2007 Solar Energ. Mater. Sol. C 91764 
5. Meng Q H and Hu J 2008 Sol. Energ. Mat. Sol. C 921260

6. Mondal S 2008 Appl. Thermal Eng. 28536

7. Stritih U 2003 Energ. Building 351097

8. Fang G, Li H and Liu X 2010 Mater. Chem. Phys. 122533

9. Hasnain S M 1998 Energ. Convers. Manag. 391127

10. Kenisarin M and Mahkamov K 2007 Renew. Sust. Energ. Rev. 111913
11. Sari A 2002 Energ. Conver. Manag. 442277

12. Alkan C and Sari A 2008 Solar Energy 82118

13. Hasan A and Sayigh A A M 1994 Renew. Energ. 469

14. Li X-X and Chen Z 2011 Acta Cryst. E67 o140

15. Toraskar M P, Kadam V J and Kulkarni V M 2009 Int. J. Chem. Tech. Res. 11194

16. Kissinger H E 1957 Anal. Chem. 291702 